preparation by the Ministry of Health of a preliminary memorandum on matters of controversy, to be circulated to all parties likely to be interested, in order to enable evidence in criticism to be heard after the recess, the committee feeling that, until the issue of such a memorandum, no useful purpose could be served by hearing further evidence on the subject-matter before them. The absence of any witnesses to speak on the industrial side of water user was, in fact, the outstanding feature of the inquiry, so far as it has gone, and it rather seems to indicate that trade and industry have been ignored by the Ministry in the prosecution of its plans. The unwisdom of such a step is surely obvious in connexion with "a question which raises interests very much wider than the interests of the Ministry of Health".

\title{
Road Width and Accidents
}

$\mathrm{T}$ HE cause of road accidents is a topic which gravely concerns every class of the community, and each attempt to determine the degree to which any one factor operates in promoting road safety deserves general attention. From the point of view of safe driving, it is probable that there is an ideal width of road for each set of traffic conditions and that, at a certain traffic density, the division of the roadway into separate 'up' and 'down' tracks becomes advisable.

It is of interest, therefore, to read in Roads and Streets (Chicago, July 1935) a paper submitted to the Highway Research Board by Prof. R. L. Morrison, of the Department of Highway Engineering at the University of Michigan, entitled "Effect of Pavement Widths upon Accidents". The main object of the author's investigation was to find evidence bearing upon the desirability of building $20 \mathrm{ft}$. roadways instead of the smaller widths which had been adopted as adequate to allow of the passage of two vehicles. It is obviously difficult to make a rigid comparison in figures between any two roads, equal or unequal in size, and this is intensified by the uncertain data obtainable regarding many accidents, and by the absence of figures relating to minor unreported accidents which might yield valuable evidence.

In this investigation, several portions of roads are dealt with, and figures are given regarding $(a) 34$ miles of $20-\mathrm{ft}$. roadway and (b) 19 miles of $18-\mathrm{ft}$. width. After eliminating those unrelated to road width and found to occur at the rate of $(a) 1.06$ and (b) 0.90 accidents per mile, the author finds that those which are affected by road width occur at the rate of $(a) 1.00$ and $(b) 1.70$ per mile. This last figure on being adjusted in order to obtain a comparison on a common basis is increased to $2 \cdot 20$, but here the reasons given are not quite convincing, though they may be justified by a personal knowledge of the roads and their conditions. If, however, we take from the detailed analyses given in the paper the figures for accidents which can be accounted to grossly careless driving - the main cause of preventable accidents-the rates are $(a) 0 \cdot 53$ and $(b) 1 \cdot 10$.

These figures strikingly support the final comparison ratio deduced by the author, whose conclusion is that, on the grounds both of the accident rate and on the relative costs, of which figures are adduced, the 20 -ft. roadway is justified. The author agrees that his data are not sufficiently extensive for general conclusions to be drawn, but suggests that the method of analysis might be adopted as a general approach to the problem. The figures dealt with are understood to relate to the accidents occurring in one year.

\section{Biological Effects of Different Regions of the Spectrum}

T the red edge of the invisible in the spectrum
have a powerful and hitherto unsuspected biological
inhibitory effect. This is reported by Lewis H. Flint,
of the Department of Agriculture, and E. D.
MeAlister, of the Smithsonian Institution (Smith-
sonian Misc. Coll., 94, No. 5, June 24, 1935), as a
result of further studies of the germination of dormant
lettuce seeds when exposed to radiation.
Previous studies by Dr. Flint had demonstrated
that such seeds could be made to germinate by
exposure to red, orange and yellow light ; and in-
hibited from germinating by irradiation with green,
blue and violet light. The inhibitory effect was
general for this upper end of the visible light spectrum,
but reached its greatest intensity at wave-lengths of
about 4200 and 4800 A. in the blue-green region.
The discovery of an inhibitory wave-band at the
red end of the spectrum which, so far as the germina-
tion of lettuce seeds was concerned, was more powerful in its effects than the entire green-blue-violet end of the spectrum, came as a complete surprise. This band lies around the critical wave-length of $7600 \mathrm{~A}$., at just about the point in the red where light ceases to be visible to the human eye.

Ordinarily its effect would be masked by the stimulating effect of the wave-lengths surrounding it, especially in sunlight. Perhaps fortunately for vegetation-although the inhibitory influence has been demonstrated only with lettuce seeds-the solar radiation in this neighbourhood is greatly reduced, owing, it is believed, to its absorption partly by oxygen in the atmosphere of the sun and partly by water-vapour in the atmosphere of the earth. Notwithstanding this absorption, however, the energy of solar radiation at this point is large.

Further studies of the possible effectiveness of this region in respect to the germination of other seeds and in respect to other phases of light sensitivity are now in progress. 